\title{
Translation and Spread of Guizhou Batik From the Perspective of 5W Mode of Communication -A Case Study of Splendid China $\cdot$ Guizhou Batik $^{*}$
}

\author{
Jixin Huang \\ School of Foreign Languages, Zunyi Medical University, Zunyi, Guizhou, 563000, China
}

\begin{abstract}
Nowadays, because the mainstream culture occupies a large number of resources in the communication field, the spread of many intangible cultural heritage has been squeezed, and batik is one of them. Guizhou batik culture, in terms of its development space, in the collision with the mainstream culture, is in a relatively disadvantaged position. However, with the accelerating process of globalization and the rapid development of information technology, we can strive to improve the translation effect by means of the combination of translation theory and communication theory, taking the $5 \mathrm{~W}$ mode of communication as the macro guidance and "function plus loyalty" proposed by Christian Nord as the principle. The $5 \mathrm{~W}$ mode of communication proposed by Lasswell not only summarizes communication as five important factors, but also provides new inspiration for translation scholars. Taking the translation practice of Splendid China $\cdot$ Guizhou Batik as an example, this paper mainly expounds the infiltration of $5 \mathrm{~W}$ mode of communication into the translation strategy and translation skills from five factors, namely, who (author and translator), says what (communication content), in which channel (media research) and with what effect, so as to enhance the spread of batik culture in Guizhou.
\end{abstract}

Index Terms—5W mode of communication, "Function Plus Loyalty" Principle, Guizhou Batik

\section{RESEARCH BACKGROUND}

Communication is a science that studies the law of information communication. Since its birth in 1940s, communication theory has made great progress. However, due to the rapid development of science and technology, and network media, it has brought unprecedented challenges to the development of traditional communication. Translation, as a carrier of communication, can give new vitality to communication.

In 1937, Lasswell pointed out in his article Propaganda and Communication Channels that American commercial interests basically controlled all communication organizations and had an important impact on the symbolic environment. After looking at this issue from a long-term perspective, he stressed the need to analyze the consequences of communication activities, that is, to consider "who gets what, when and how". This has initially formed his $5 \mathrm{~W}$ mode. (Harold D. Lasswell, 1937) Based on the 5W mode of communication and the principle of "function plus loyalty" proposed by Christian Nord, through on-the-spot investigation, this paper studies the translation of Guizhou batik, and takes the translation of Splendid China - Guizhou Batik as an empirical study. On the basis of following the style of the original text, we should make a cross-cultural awareness turn and strive to achieve the goal "Let China go to the world, let the world understand China", and then export Guizhou batik to the outside world in English, so that foreign friends can better understand the breadth and profundity of Guizhou traditional handicraft - batik art, and better understand the local cultural value and economic value of Guizhou batik art.

\section{THE 5W MOdE OF COMMUNiCATION}

\section{A. Who -- Communicator}

"Who" is the communicator, responsible for the collection, processing and transmission of information in the process of communication. Communicators are the starting point and one of the centers of communication activities. The communicator can be a single person, a collective or a special organization, acting as a gatekeeper. The translation of national culture requires the joint efforts of all types of translators in order to convey the voice of national culture in an all-round way. The experience of Chinese culture translation shows that the works favored by foreign readers are often produced by foreigners. However, few foreign translators are proficient in Chinese, and few of them know a certain minority language, which can not meet the needs of national culture translation. Therefore, the need of Guizhou

\footnotetext{
* This paper is supported by "Research Foundation on Humanities and Social Science of the Education Department of Guizhou Province (2020QN073)"
} 
minority culture translation naturally falls on the Chinese who take Chinese or a minority language as their mother tongue. In this translation practice, the communicators are the authors and the translators. Splendid China . Guizhou Batik was edited by He Chen and Yang Wenbin. He Chen, female, was born in 1976. In 2003, she graduated from Beijing Institute of Fashion Technology with a master's degree and then graduated from the Minzu University of China with a doctorate in cultural heritage protection. Mainly engaged in ethnic costume culture and weaving embroidery dyeing process research, she is now the deputy research librarian of the Central Museum of Nationalities. In recent years, she has published many monographs such as Miao Batik and Folk Costumes. While the translators are a translation team composed of translation teachers in a university. Before the translation practice, the team members have collected a large number of materials related to $5 \mathrm{~W}$ mode of communication and Guizhou batik. In the early stage, the project host published a related paper around the $5 \mathrm{~W}$ mode of communication. The participants of the project include two associate professors, two lecturers and two teaching assistants. Five of them are young backbone teachers of the School of Foreign Languages, with high scientific research ability and rich teaching experience. The other is deputy director of the office, with strong comprehensive coordination ability, writing skills and high computer level. Therefore, both the authors and the translators are well prepared for batik culture translation under the $5 \mathrm{~W}$ mode of communication.

\section{B. Say What -- Content}

"Say what" refers to the content of the message, which is a combination of information composed of a group of meaningful symbols. Symbols include linguistic symbols and non-linguistic symbols. Guizhou is a big province of ethnic minority cultures, so the resources of ethnic culture translation and communication are very rich. The choice of ethnic culture translation content is very important, which should be in line with the fundamental purpose of cultural communication. Through translation, Guizhou's national culture will go to the world, enhance the world influence, and promote the development of Guizhou's tourism economy. The research object of this paper is Splendid China Guizhou Batik, supported by National Publishing Foundation of China, edited by He Chen and Yang Wenbin, published by Suzhou University Press in 2009, and won the First Chinese Outstanding Publications Book Award and the First China Publishing Government Award. The book has a total of more than 140, 000 words and five chapters: Chinese Batik history, Guizhou batik technology, Guizhou batik style, Guizhou batik patterns and Guizhou batik culture. It not only records Guizhou batik ethnic handicrafts with pictures and texts, but also introduces the folk customs and cultural ecology in Guizhou batik. Therefore, the book has great value for international communication.

\section{In Which Channel -- Media}

"Channel" is the medium or material carrier through which information must be transmitted. It can be letters, telephone and other interpersonal media, and can also be newspapers, radio, television and other mass media. Books and newspapers are the main media of Guizhou ethnic culture translation. However, we should create different forms of translation versions (such as edited version, annotated version and printing version), to adapt to different reader groups, and expand the range of readers and social influence of national culture. In addition, the network is another powerful promoter for the spread of Guizhou ethnic minorities. With the help of network technology, Guizhou national culture can be spread through the establishment of websites, blogs, forums and so on. With the rapid development of mobile media, mobile books, mobile journals, mobile newspapers, mobile radio, mobile TV, etc., can be used as a good communication channel to promote Guizhou ethnic minority culture. Translation is a cross-cultural information communication activity. Based on the translation practice of Splendid China $\cdot$ Guizhou Batik, this paper aims to make the ethnic national culture of Guizhou batik go to the world, and promote the development of Guizhou tourism economy through traditional means such as network electronic media or translated works.

\section{To Whom -- Audience}

"To whom" is the receiver or the audience. Audience is the general name of all the receivers, such as readers, audience, etc. it is the ultimate object of communication. Audience (target reader) plays an important role in the translation activities. It is the receiver of information spread and the acceptor of translation quality. Without the active participation of the audience, translation can not be carried out successfully. The practical translation experience shows that only those messages that conform to the cultural values, cognitive structure and psychological expectations of the minority cultural, so audience can achieve satisfactory communication effect. Therefore, in the process of translating and spreading national culture, it is necessary to have a full understanding of the history and culture, mode of thinking, values, aesthetic habits and demand levels of the target readers. After this translation practice, we will share the translated works with foreign friends through e-magazine, and adjust the translation based on their feed-backs after reading.

\section{E. With What Effects -- Effect}

"Effect" refers to the reaction caused by the information to the audience at all levels of cognition, emotion and behavior. It is an indispensable part of the whole communication process and an important yardstick to test the success of communication activities. The study of Guizhou ethnic minority culture's translation and communication depends on its effect, which refers to the information sent by the main body of translation, and transmitted to the target language 
readers through certain media, causing the changes of the audience's ideas and behavior, or the influence and result on a certain society, so as to realize the communication intention of translation. The study of the communication effect of ethnic culture translation should not only focus on the macro analysis of social effect, but also on the micro analysis of individual effect.

\section{The PRINCIPLE OF "Function Plus Loyalty"}

In the 1970s, functionalist translation theory emerged in Germany. In 1991, Christian Nord put forward the principle of "function plus loyalty" in discourse analysis in translation, which overcomes some shortcomings of functional skopos theory, comprehensively summarizes and perfects functionalist theory and expands its influence. Nord puts forward the principle of loyalty to solve the relationship between cultural differences and the participants of translation behavior. According to Nord, "function" refers to the translation purpose for the receiver, while "loyalty" refers to the interpersonal relationship among the translator, the author and the receiver. In Zheng Yang's translation practice from the perspective of communication studies, he points out that translation from the perspective of communication studies is no longer the linguistic equivalence between the source language and the target language, but needs a more dynamic and systematic method to study the real connotation of translation as an important way of information and culture transmission. (Zheng Yang, 2015) Therefore, the translation theory and the 5W mode of communication have a high degree of agreement. Combining the two to study the translation and communication of the ethnic culture of Guizhou batik will get twice the result with half the effort.

\section{TRANSLATiOn SKILlS AND CASE STUdiES}

\section{A. Literal Translation and Annotation}

Due to the great cultural differences between China and foreign countries, many words and expressions with cultural characteristics lack parallel texts. If only literal translation is used, the connotation of some culture loaded words in the source text may be partially missing. Literal translation of some cultural differences can not accurately reflect the meaning and charm of the original text. Therefore, when literal translation is used to reflect cultural differences, annotations can be added to make up for the "blank area" between cultures, so that readers can experience foreign cultures. In addition, due to the uneven understanding of Chinese culture by the target readers, it may be difficult for some people to understand the literal translation, and thus unable to understand its deeper meaning; If only free translation is used, it will be easier for the target language readers to read, but it will lose the purpose of cultural transmission and output. Therefore, literal translation and annotation can be used to achieve the purpose of spreading culture loaded words.

\section{E.g.1 ST: 清雍正时期推行大规模的改土归流。}

TT: During the Yongzheng Period of the Qing Dynasty, a large-scale reform of the policy of Change from Tuguan to Liuguan (Tuguan means the native officers, Liuguan means the officers appointed by the feudal government) was carried out.

When talking about the environmental factors of Guizhou batik, the author introduces the administrative division and bureaucratic election system of Guizhou in the Yongzheng Period of Qing Dynasty. In this sentence, the author refers to the system of "改土归流", that is, a political measure implemented in southwestern minority areas in the Ming and Qing Dynasties. Southwest China is a place where Miao, Yao, Zhuang, Yi and other ethnic minorities live together. In the early Ming Dynasty, the Tusi system of the Yuan Dynasty was followed. In these areas, the upper class members of ethnic minorities were appointed as officers at all levels, which was called "Tusi". Tusi office includes Xuanwei, Xuanfu, Zhaozhao, Anfu and so on. In order to fight for territory, there were constant wars between Tusi. After calming down the war, the Ming government replaced the Tusi in these areas and sent "Liuguan" who could be transferred at any time to rule. This method is called "改土归流". If literally translated as Change from Tuguan to Liuguan, readers can not understand what are Liuguan and Tuguan, and can not achieve the Fifth W--- With what effect in 5W mode of communication. Therefore, here the way of annotation to explain Liuguan and Tuguan is used, so that readers can have a deeper understanding of the policy of Change from Tuguan to Liuguan to the local government in Yongzheng period, and then further understand the influence of the policy on the development of batik at that time.

E.g.2 ST: 据《后汉书·南蛮传》《搜神记》等记载, 秦、汉时期,被称为“盘瓠蛮”、“武陵蛮” 的苗族先民“织绩木皮、染以草实，好五色衣，制裁有尾形......裳斑斓”。

TT: According to the records of The Book of the Later Han: Biography of Nan Man and Stories of Immortals, the ancestors of the Miao nationality, known as "Panhu man"1 and "Wuling man" 2 in the Qin and Han Dynasties, "weave wood veneer, dye with grass, dress in five colors, cut in the tailed shape...colorful clothes."

\footnotetext{
1 Ancient clan name. Panhu man got its name from the totem of Panhu. During the Qin and Han Dynasties, he lived in Wuling County (now western Hunan, eastern Guizhou and Southwest Hubei), Changsha County (now central Hunan and southern Hunan).

2 In Han Dynasty, it was a general term for ethnic minorities distributed in today's western Hunan, Southwest Hubei and other areas. It is named because it is located in Wuling county.
} 
When introducing the return of batik to the southwest after the Song and Yuan Dynasties, the author mentions the migration of ethnic minorities to the southwest, which involves two words “盘瓠蛮”、“武陵蛮”. In translation, if they are transliterated as Panhuman and Wulingman, the readers should not be able to understand the meaning of these two words. Therefore, the translator translates them as Panhu man and Wuling man. Although there is only one space mark between them, the translator lists man as a single word. Readers will know that this represents a kind of people. On this basis, through the annotation of "Panhu man" and "Wuling man", it is pointed out that this kind of appellation appeared in the Qin and Han Dynasties, which got its name from totem or local county name, and especially refers to the minority. This translation not only conforms to Nord's "loyalty" principle, but also enables readers to understand the appellation and dress of the ethnic minorities in the Qin and Han Dynasties, so as to achieve the purpose of cultural communication.

E.g.3 ST: 贵州地貌以高原山地居多,素有“八山一水一分田”之说。

TT: Guizhou's landforms are mostly plateau mountains, known as "eight mountains, one water and one field"3.

When introducing the environmental factors of Guizhou batik, the author mentioned the geographical location and features of Guizhou, so as to highlight the fact that Guizhou ethnic minorities live in a relatively closed social environment, so hand-made batik can be well preserved. In describing the landforms of Guizhou, the author quoted the saying of “八山一水一分田”. If it is just translated as "eight mountains, one water and one field", it may cause misunderstanding to readers, which means that there are only eight mountains, one river and one piece of land in Guizhou. Therefore, in order to eliminate the readers' barriers to understanding, literal translation and annotation can be used to further explain that Guizhou is a place with many mountains and few rivers and fields, and the "eight" and "one" in the sentence are only approximate numbers.

\section{B. Transliteration and Annotation}

In translation, translator should give full play to the subjectivity of the translator, create a cultural atmosphere for the target audience, and lead the readers to experience the cultural atmosphere between the lines and be in the cultural system described in the text. This means that there is no invariable norm to limit the text in literary translation, and translation itself means the contrast and reconciliation of different cultural patterns. (Nord, 1997) Transliteration can retain the Chinese phonology, while annotation can explain its cultural connotation and characteristics to some extent, so that foreign readers can appreciate Chinese traditional folk customs. It can let readers contact the context, which is conducive to the spread of words with Chinese cultural characteristics. However, only transliteration is meaningless to the readers who do not understand Pinyin, which will cause some obstacles to the readers' understanding. Therefore, transliteration plus annotation can be used to convey the cultural connotation.

E.g.4 ST: 因此人们积极寻找替代品, 从而促使了灰贱的产生。灰烦最早出现在宋代, 早期 是直接用“灰药”染青。

TT: Therefore, people actively looked for substitutes, which promoted the emergence of "Hui Xie" (meaning printing and dyeing with alkaline raw materials such as lime and plant ash as anti dyeing agent, so it is also called alkaline printing). "Hui Xie" first appeared in the Song Dynasty. In the early period, it was directly dyed with "Hui Yao" (meaning the paste made of lime).

When describing the return of batik to the southwest after the Yuan and Song Dynasties, the author mentions that batik needs a lot of wax. However, the beekeeping industry in Tang Dynasty was still underdeveloped, the production of beeswax was small, and the important raw materials for batik were extremely scarce. It mainly depended on the southwest and other places to pay tribute, so people used “灰颉” as a substitute. In this example, there are two expressions of traditional printing process “灰缬” and printing material “灰药”. Looking back on the development history of textile printing in China, we can see that the ancient printing process has spanned thousands of years. There are many kinds of textile printing in ancient times, and the process is very exquisite, which is still shining. Many printing processes have been listed in the National Intangible Cultural Heritage and become the precious wealth of the Chinese nation. Therefore, understanding the ancient printing process and exporting the traditional printing process is conducive to promoting the spread and development of printing technology. If it is transliterated directly as "Hui Xie" and "Hui Yao", it is meaningless Pinyin for the audience. In order to achieve the purpose of cultural communication, we should clearly explain the specific reference of "Hui Xie" and "Hui Yao". After consulting experts, from the perspective of printing process characteristics, ancient textile printing process is mainly divided into direct printing and anti-dyeing printing, "Hui Xie", as one of the four anti-dyeing printing techniques, has an important position. "Hui Xie" is a process of printing and dyeing with alkali raw material lime and plant ash as anti-dyeing agent, so it is also called alkali agent printing. The process is similar to today's blue calico. The "Hui Yao" in this paper is not a kind of medicine, but a paste made of lime, which is missed on the grey cloth through the pattern. Therefore, in the translation of “灰顺”, we emphasize its raw materials and printing and dyeing methods, which is translated as "Hui Xie" (meaning printing and dyeing with alkaline raw materials such as lime and plant ash as anti dyeing agent, so it is also called alkaline printing; “灰药” is translated as "Hui Yao" (meaning the paste made of lime) to stress that its essence is a paste mixed with lime.

\footnotetext{
${ }^{3}$ Guizhou Province has more mountains, less water and less farmland.
} 


\section{E.g.5 ST: 清嘉庆时甘肃武威人张澍《黔苗竹枝词》中的“蜡绘花衣锦裙裳,振铃跳月斗新妆”。 \\ TT: In "Zhu Zhi Ci Poem (seven words a line, eight lines) in Guizhou Miao Nationality" by Zhang Shu, a Wuwei native of Gansu Province in Jiaqing period of Qing Dynasty, "With wax painted clothes and brocade dresses, people ring the bell and Tiao Yue}

(Tiao means dance and Yue means the moon) 4 to compete for beautiful make-up."

When introducing the development history of Southwest batik, the author chooses more poems to describe batik costumes and ethnic customs. For example, 《黔苗竹枝词》 in this sentence, the translator doesn’t translate “竹枝” into bamboo branch, but transliterated as "Zhu Zhi", because in the first chapter of the translation of Lusheng, it has emphasized the use of orchestral instruments made of bamboo branch, so here bamboo branch actually refers to musical instruments, so we can use the previous method of transliteration of Lusheng to ensure the consistency of the translation. “词” in 《黔苗竹枝词》 is not the lyric, but the "Ci" in poetry, so it is translated into "Ci Poem" (seven words a line, eight lines), so that foreign readers can better understand the meaning of "Ci" in Chinese poetry. In addition, “月” (the moon) has a beautiful cultural image in Chinese traditional culture, such as "full moon" symbolizes reunion, "Yuelao" symbolizes love; "Moon" especially symbolizes love in Guizhou ethnic minority culture, such as "Tiao Yue" in this example, which refers to a custom of Miao, Yi and other people. On the moonlit night in early spring or late spring, especially on the night of Mid Autumn Festival, unmarried young men and women gather in the field to sing and dance. People who love each other can become husband and wife through various activities. Therefore, the translator chooses the form of transliteration and annotation, which is translated as Tiao Yue (Tiao means dance and Yue means the moon). In this way, foreign readers can understand the meaning of the Pinyin of Tiao Yue. Similarly, the "Yue Chang" in the first chapter refers to the Miao custom, where unmarried men and women woo and jump to the ground. The translator also uses transliteration and annotation, which is translated as "Yue Chang (Yue means the moon and Chang means a site): Miao custom, unmarried men and women journey jump on the ground."

\section{E.g.6 ST: 在染色技术上，唐代的夹巅、蜡线、绞倾等染色方法已成熟并得到普遍应用。 \\ TT: In terms of dyeing technology, the dyeing methods of "Jia Xie" (meaning indigo} printing fabric), "La Xie" and "Jiao Xie" (meaning tie-dye) in Tang Dynasty were mature and widely used.

In introducing the popularity of batik in the Central Plains since the Wei and Jin Dynasties, the author mentions three kinds of batik techniques, 夹顿、蜡傾、绞傾. In translation, the method of transliteration and annotation is adopted, which is translated as "Jia Xie" (meaning indigo printing fabric), "La Xie" and "Jiao Xie" (meaning tie dye), so that readers can not only understand the pronunciation of the three skills, but also understand the meanings behind them. Because La Xie has been annotated and explained in the first chapter, there is no repetition here; at the same time, when translating the three processes, there is no detailed description of their production steps or making process, because in the following chapter "The Making and Dyeing of Indigo", there are detailed explanations of various processes, so the translator chooses to put the corresponding English in the following chapter. For example, "Jia Xie" is a kind of hollow-out double-sided anti dyeing printing technology. It uses two patterns with the same engraving pattern to clamp the fabric, and then immerses it into the dyeing vat for dyeing. The clamped part can not penetrate the dye solution, and retains the original color. The other parts of the cloth are dyed with color, thus forming a rich pattern. Through the description of words and pictures, there will be a dynamic balance among the author, the translator and the reader, which conforms to Nord's "function" principle and achieves the purpose of cultural communication.

\section{Free Translation}

In Ten Lectures on Literary Translation, Professor Liu Chongde defines free translation as "What is free translation? It may be defined as a supplementary means to mainly convey the meaning and spirit of the original without trying to reproduce the sentence patterns or figures of speech. And it is adopted only when it is really impossible for translators to do literal translation." (Liu Chongde, 1991, p.53) It can be seen that free translation refers to the translation of content, which emphasizes fluency rather than formality. When it is impossible to translate according to the literal meaning of the original text, and the reader of the target language can not understand it, and can not effectively grasp the deep meaning of the original text, we should break the language form of the original text and adopt free translation. When it comes to different cultures, "According to different cultural traditions, it is also a basic translation skill to adjust the language form in the original text to the language form accepted by the target culture." (Wills, 2001, p.21)

E.g.7 ST: 当时主要的手工业部门掌握在官府手中,仅官营染色业就细分为青、㖓、黄、白、 皇、紫六作。

TT: At that time, the main handicraft industry was in the hands of the government. The government-run dyeing industry was divided into six categories: indigo, deep red, yellow, white, black and purple.

In describing the development of dyeing industry in Tang Dynasty, the author mentions six categories of

\footnotetext{
${ }^{4}$ Tiao Yue refers to a custom of Miao and Yi people. On the moonlit night in early spring or late spring, especially on the night of Mid Autumn Festival, unmarried young men and women gather in the field to sing and dance. People who love each other can become husband and wife through various activities.
} 
government-owned dyeing industry, and emphasizes the diversity of dyeing styles, innovative technology and cultural inclusiveness of Tang Dynasty. In the above example, the six categories are classified according to the dyeing colors of batik, which are 青、绛、黄、白、皇、紫. The color "青" should be paid attention to in translation. In fact, "青" is not just one color. It can be divided into many kinds. For example, "青" is a cool color between indigo and grass-green, which is commonly used in painting. "青" is also commonly used in blue and white porcelain in Qing Dynasty, which is actually a blend of blue and a little green. In Chinese vocabulary, "青" may represent blue, green and black. As an old saying goes, "青" is much better than "蓝" ("青": cyan pigment. "蓝": Polygonum, a kind of grass that can extract pigment. "青" is extracted from Polygonum, but its color is darker than that of Polygonum. It means that people can improve after learning or education. It is often used as a metaphor for students surpassing their teachers or successors.) Here, the color "青" means blue with a little purple. In addition, there are also many classical Chinese, "青" may also stand for black. In most cases, it depends on the context. In the development of dyeing industry in Tang Dynasty, people mainly extracted dyes from plants, so "青" should be translated as "Indigo". According to its English explanation, indigo means "decisive subshrub of southern Asia having pink leaves and clusters of red or pure flowers; a source of indigo dye", so it may be more helpful for target readers to understand the color "青".

E.g.8 ST: 女神高鼻深目,胸怀袒露, 颈佩顼珞, 臂饰环钏, 手持盛满了果实的丰饶角。

TT: The goddess has a Roman nose and deep eyes, with a bare chest, a necklace of precious stones around her neck, a bracelet on her arm, and a cornucopia in her hand.

When introducing the existence of batik in ancient China, the author mentions that in 1959, archaeologists in Xinjiang discovered a tomb in the late Eastern Han Dynasty (2nd century A.D.) at the Niya site in Minfeng County, Xinjiang. Two pieces of blue and white calico were unearthed from the tomb, which is the earliest known piece of calico in China. Among them, a piece of cotton cloth has been missing in the center, only half a foot and a lion's tail can be seen. In the lower left corner, there is a 32-cm square box with a bust of the goddess. The description of the cotton cloth is "女神高鼻深目,胸怀祖露, 颈佩顼珞, 臂饰环钏, 手持盛满了果实的丰饶角". In the translation of "高鼻", the translator doesn't translate it into "high nose", because the frequency of "high nose" in search engines is not high. Therefore, it doesn't belong to a high frequency word, so this usage may cause some misunderstanding for foreign readers. Then, the free translation method is adopted here, translated as Roman nose, which is in line with the westerners' cognition of "高鼻". In addition, in the 5W mode of communication, the third W refers to in which channel, that is, media. In order to further promote the translation with the help of technology, the translator has made the translation into e-magazine with words and pictures, so that readers can gain a more powerful visual impact.

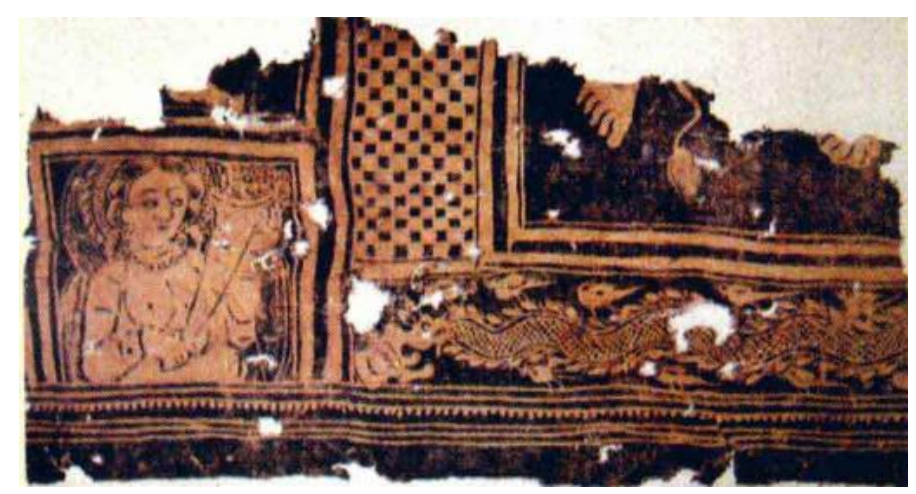

\section{E.g.9 ST: 辽阔的疆土和雄厚的国力成就了唐代海纳百川的胸怀，也形成了染织风格的 多样性和文化的包容性,其社会经济发展迅速，手工业兴盛发达,纺织业、染色 业也得到相应的发展。}

TT: The vast territory and strong national strength of the Tang Dynasty made it possible for the Tang Dynasty to welcome all the diversities.

In describing the dyeing and weaving style of the Tang Dynasty, the author talks about the diversity of its style with the idiom "海纳百川" to describe it. "海纳百川" refers to a wide range of things with inclusiveness. As we all know, Chinese idioms are also an important part of Chinese traditional culture, so it is particularly important to spread their concepts to the outside world. However, if we literally translate it as "embrace all rivers and seas" or "all rivers run into sea" without considering the "to whom" of the fourth $\mathrm{W}$ in the $5 \mathrm{~W}$ mode of communication, readers may be surprised: why the rivers and seas appear here when talking about the various styles of batik. Therefore, the translator uses free translation to translate it into "welcome all the diversities" to emphasize the inclusiveness.

\section{CONCLUSION}

Peng Jie (2013) pointed out that, for a country and a nation, cultural soft power is also related to the prosperity of the 
country and the rise and fall of the nation. Translation can build a platform for spreading national culture, highlighting national discourse power and enhancing cultural soft power. At the same time, it is also one of the effective ways to publicize China's ethnic minority culture and let the world know and identify with the cultural identity of the Chinese nation. Guizhou Folk printing and dyeing process is an important part of Chinese folk art, and is one of the typical representatives of folk arts that Chinese people have always been proud of. It has a long history, involves many nationalities, uses a wide range of materials, and produces a variety of products, reflecting the wisdom and creativity of the people of all ethnic groups in Guizhou (Zhou Chenchen, 2015). Based on the 5W mode of communication proposed by Lasswell, which includes five factors: communicator, content, channel, audience and effect, this paper attempts to translate Splendid China . Guizhou Batik according to Christian Nord's principle of "function plus loyalty". In translation practice, it embodies the interdisciplinary combination of communication and translation, and provides new inspiration for translation scholars.

\section{REFERENCES}

[1] Harold D. Lasswell. (1937). Propaganda and the Channels of Communication, Education against Propaganda Cambridge. MA: National Council for the Social Science Studies.

[2] Liu Chongde. (1991). Ten Lectures on Literary Translation. Beijing: China Translation and Publishing Corporation.

[3] Nord, Christiane. (1991). Text Analysis in Translation: Theory, Methodology, and Didactic Application of a Model for Translation-Oriented Text Analysis. Amsterdam-Atlanta: Rodopi.

[4] Nord, Christiane. (2001). Translation as A Purposeful Activity---Functionalist Approaches Explained. Shanghai: Shanghai Foreign Language Education Press.

[5] Peng Jie. (2013). Research on the Translation of Cultural Publicity of Ethnic Minorities in Yunnan from the perspective of Skopos Theory. Journal of Suzhou Education Institute, 16, 61-63

[6] Willss, Wolfram. (2001). The Science of Translation, Problems and Methods. Shanghai: Foreign Language Education Press.

[7] Zhou Chenchen. (2015). Study on Folk Printing and Dyeing Process in Guizhou. Master Dissertation, Guizhou Minzu University.

[8] Zheng Yang. (2015). Translation Practice from the Perspective of Communication. English Square, 5, 136-137.

Jixin Huang was born in Zunyi City, Guizhou Province, China in 1987. She got a Bachelor's degree in English in 2011, a Master's degree in Translation in 2014 from Guizhou University. She is currently a lecturer at School of Foreign Languages of Zunyi Medical University, Guizhou, China. Her research interest lies in the teaching and practice of translation and interpretation. 